In particular, responsibility for education, the most sensitive political issue, was placed exclusively in the hands of the states. The constitution allowed the federal government to offer only short-term project money to universities.

This admirable philosophy was not without problems. Universities in the more cash-strapped states, such as Saarland in the west and Mecklenburg-Vorpommern in the east, could not compete with universities in rich states such as Bavaria and Baden-Württemberg in the south. And frustrated successive federal governments were unable to exert political influence to force universities to raise their game and become competitive. Despite Germany's general wealth, barely half a dozen of its universities regularly appear in the Shanghai Jiao Tong University ranking of the world's top 100 universities. The two most successful ones - the Technical University of Munich (now placed forty-seventh) and the Ludwig Maximilians University of Munich (placed fifty-fourth) - are in Bavaria. The University of Heidelberg in Baden-Württemberg comes in third, at sixty-second.

For decades, the federal and state governments have colluded to make exceptions to the strict federalization of universities in ways - such as in infrastructure - that did not allow the federal government to exert political influence. A 2005 agreement to create the multibillion-euro Excellence Initiative - which will expire in 2017 after two rounds - was something of an exception. The competition for graduate schools, research clusters and the coveted title of 'elite university' indirectly allowed the federal government to exert its political will.

So why the 2006 decision to stop money flowing to universities from the federal government? Probably because the 2006 federal reform was a much wider-ranging attempt to clarify responsibilities between governments on both levels that had, over the decades, been rendered fuzzy by the introduction of innumerable exceptions to the divisions laid out in the 1949 constitution. Universities were a tiny part of this. Although experts saw the problems immediately, they could not persuade politicians to delay a highly complicated agreement to negotiate an apparent detail.

"The federal
government
could do even
more to steer
academic science
in Germany
towards sustained
competitiveness."

German schools certainly need greater investment, and the federal government is well placed to help. But in this sensitive area, the states do not want the federal government to share in decisions on how its donated money is spent. This is unacceptable to the government, which until 2006 had always participated in decisions about the co-financing of university infrastructure and equipment through its inclusion in the German Council of Science and Humanities, a high-level committee of scientists and politicians.

The debate over schools could involve years of painful negotiation, and German universities should not be made to wait. If the Social Democrats and Greens drop their opposition to the two-word addition to the constitution now, that change could be in place by March 2013. They should do so. The federal government could then, for example, directly ensure the survival beyond 2017 of successful institutes created in the Excellence Initiative, even if the states in which they are located cannot give them permanent financing. And the government could do even more to steer academic science in Germany towards sustained competitiveness - not to usurp the states' power but to give them financial breathing space.

\section{Final say}

\section{Ongoing controversy over work at Japan's Tohoku University must be resolved.}

I $\mathrm{t}$ is not easy for universities to investigate their own researchers. But as a case at Tohoku University shows, it is especially difficult in Japan - particularly when the scientist concerned is the university's president.

When concerns were raised in 2007 about irregularities in the research of Akihisa Inoue, who specializes in making metallic glasses, the university formed a committee to look into the matter. The committee determined that there was no case to answer and that the matter need not be investigated formally. But the decision satisfied few of his doubters, who criticized the committee for being heavily populated by university administrators whom Inoue had appointed to their posts (but not to the committee). The university says that there was no conflict of interest.

Four years later, and with claims of problems in Inoue's papers accumulating, the university formed another committee. This time it got an eminent outsider, Akito Arima, former president of Tokyo University, parliamentarian and minister of education, to lead. The committee focused on retractions of six papers on which Inoue had been an author.

The committee concluded that the duplicate submissions that led to the retractions were an example of poor, but somewhat accepted, practice in the field of materials science. Duplicate publications, the report said, were bad, but "different from practices such as FFP [falsification, fabrication and plagiarism], which clearly have a negative impact on research." In a formal statement, Inoue apologized and said that the university would quickly implement the report's recommendations.

The judgement was surprisingly light. Six retractions is a serious matter, although they may simply indicate that Inoue - who has more than 2,500 papers to his name - was trying to move too fast. As Inoue has told Nature, his laboratory did not always check its papers to ensure that its research was cited properly.

Then, in April 2011, the Japan Science and Technology Agency (JST) formed a committee to find out whether the retractions, corrections and other allegations had undermined the results of a project it had funded between 1997 and 2002. It found no reason to question the main findings, but concluded that 5 of 27 high-impact papers were duplicated in other papers by Inoue's laboratory. But neither of these latest committees, as both acknowledge, investigated the more serious allegations against Inoue concerning irreproducibility of results (see Nature 470, 446-447; 2011). Inoue denies any manipulation of data, and there is no evidence that he has committed any scientific misconduct.

The JST, in accordance with its policies, has now requested that the university look into the allegations. The university says that it will do so, but will give no details about the composition of the committee, or about the investigation's mission, scope or expected date of completion.

Unlike countries such as the United States, Japan has no final arbiter for such issues. The Office of Research Integrity in Rockville, Maryland, for instance, as well as many funding agencies, can aggressively investigate allegations. Even if they don't satisfy everyone, their decisions are final, and for the most part fair.

The primary responsibility for investigating should always remain with the university, research institute or relevant scientific society. But Japan needs a procedure to oversee the committees that make these judgements. The authors of the JST report suggest that the Science Council of Japan (if given the necessary funding to repeat experiments) could fit this role. Such a body seems worthwhile, and $\rightarrow$ NATURE.COM To comment online, click on Editorials at: go.nature.com/xhunqv it could very well have closed the arguments at Tohoku University that refuse to die even after use the situation at Tohoku to create a mechanism to handle situations such as these. nearly five years. Japan's policy-makers should 